\title{
Differences in liver glycogen-synthase phosphatase activity in rodents with spontaneous insulin-dependent and non-insulin-dependent diabetes
}

\author{
M. Bollen, S. Keppens and W.Stalmans \\ Department of Biochemistry, Faculty of Medicine, Catholic University of Leuven, Belgium
}

\begin{abstract}
Summary. The activation of glycogen synthase after addition of glucose to isolated hepatocytes became impaired in BB rats after the development of insulin-dependent diabetes. This defect was associated with a decreased hepatic synthase phosphatase activity. Both features correspond closely to previous observations on alloxan-diabetic rats. In contrast, in hyperinsulinaemic $\mathrm{db} / \mathrm{db}$ mice with a similarly increased plasma glucose concentration (non-insulin-dependent diabetes), the synthase phosphatase activity was essentially
\end{abstract}

normal. We conclude that the decreased hepatic synthase phosphatase activity in insulin-dependent diabetes in rodents is due to the lack of insulin, rather than to the increased intrahepatic glucose concentration.

Key words: Insulin-dependent diabetes, non-insulin-dependent diabetes, glycogen synthase, phosphoprotein phosphatases, glycogen synthase phosphatase, glycosylation.
The response of the normal liver to a glucose load involves sequentially the inactivation of glycogen phosphorylase and the activation of glycogen synthase, the rate limiting enzyme of glycogen synthesis [1]. Addition of glucose reproduces these changes in isolated liver cells. In experimentally induced diabetes the hepatic response to glucose becomes deficient a few days after the administration of alloxan [2]. When hepatocytes from such animals are challenged with glucose the inactivation of phosphorylase proceeds normally, but the ensuing activation of glycogen synthase is grossly impaired. This intrinsic defect has been explained by a functional loss of the glycogen-bound glycogen-synthase phosphatase [3]. In an attempt to clarify the underlying mechanism, we have now examined these parameters of glycogen synthesis in the liver of rodents with different types of spontaneous diabetes.

\section{Materials and methods}

\section{Handling of animals and livers}

Animals of either sex had free access to food and water until killing (between 09:00 and 10:00 hours). Plasma was prepared from blood collected on EDTA. As a model for insulin-dependent diabetes we used $\mathrm{BB} /$ Thi rats, about $60 \%$ of which develop an autoimmune diabetes around the age of 14 weeks. Various data were collected from 11 diabetic rats (4-5 days after the onset of glycosuria) and from 11 non-diabetic littermates. Hepatocytes were isolated and incubated as described [2] in the presence of the indicated glucose concentration. Before the liver was perfused a lobule was isolated and

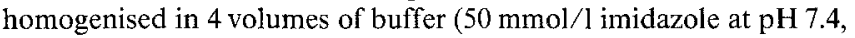
$0.5 \mathrm{mmol} / 1$ dithiotreitol and $0.25 \mathrm{~mol} / 1$ sucrose) for the assay of glycogen-synthase phosphatase. For the assay of glycogen synthase a sample of the homogenate was immediately added to a mixture of inhibitors of protein phosphatases and kinases [2]. For the determination of glycogen a sample was heated in the presence of $2.5 \mathrm{~mol} / \mathrm{l}$ $\mathrm{KOH}[4]$.

The mice were of the inbred $\mathrm{C} 57 \mathrm{BL} / \mathrm{KsJ}$ strain. The wild type $(+/+)$ was compared with homozygotes $(\mathrm{db} / \mathrm{db})$ for an autosomal recessive mutation that leads to the development of a non-insulindependent diabetes. The animals were killed at 7 to 22 weeks of age. The livers were homogenised as described above.

\section{Assays}

Glucose was determined with glucose oxidase, and glycogen was measured as glucose after digestion by amyloglucosidase [4]. Insulin was determined with an immunoassay according to Heding [5]. Mouse and rat insulin and anti-pork-insulin guinea pig serum were purchased from Novo Industri (Bagsvaerd, DK). Glycogen synthase was assayed in the presence of $10 \mathrm{mmol} / 1 \mathrm{Na}_{2} \mathrm{SO}_{4}$ (synthase $a$ ) or $10 \mathrm{mmol} / 1$ glucose-6-P (synthase $a+b$ ) as before [2]. One unit of synthase converts one $\mu \mathrm{mol}$ of substrate/min in the appropriate assay conditions. The activity of glycogen-synthase phosphatase was derived from the rate of activation of purified dog liver synthase $b$ by liver homogenates at a final concentration of $2 \%$ [3]. One unit of synthase phosphatase activates 1 unit of synthase $b /$ min. Other assays and the source of other materials have previously been described [2-4]. 
Table 1. Some body, plasma and liver characteristics in rodents with spontaneous diabetes

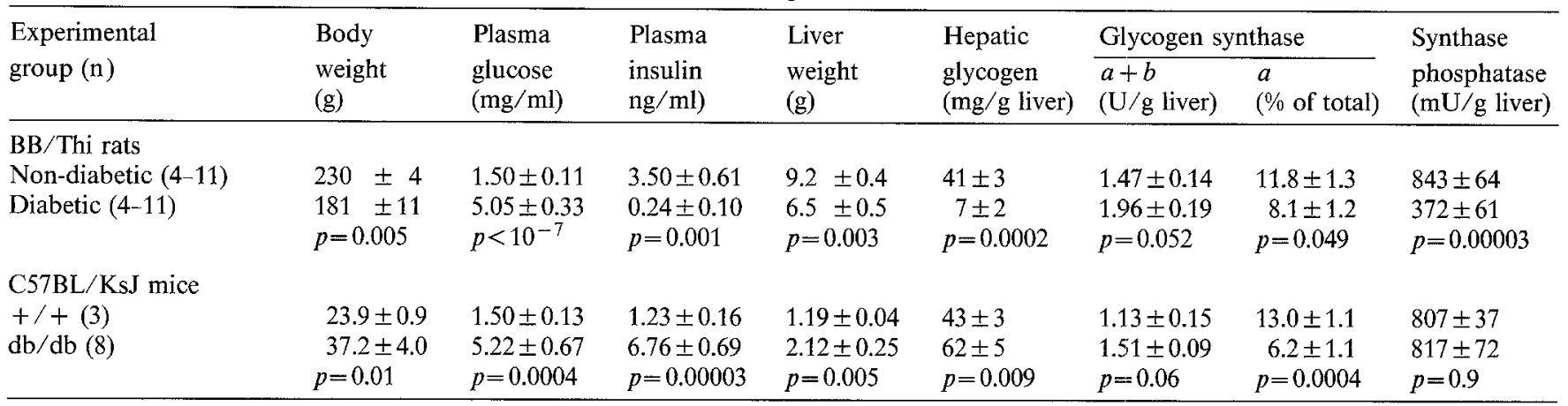

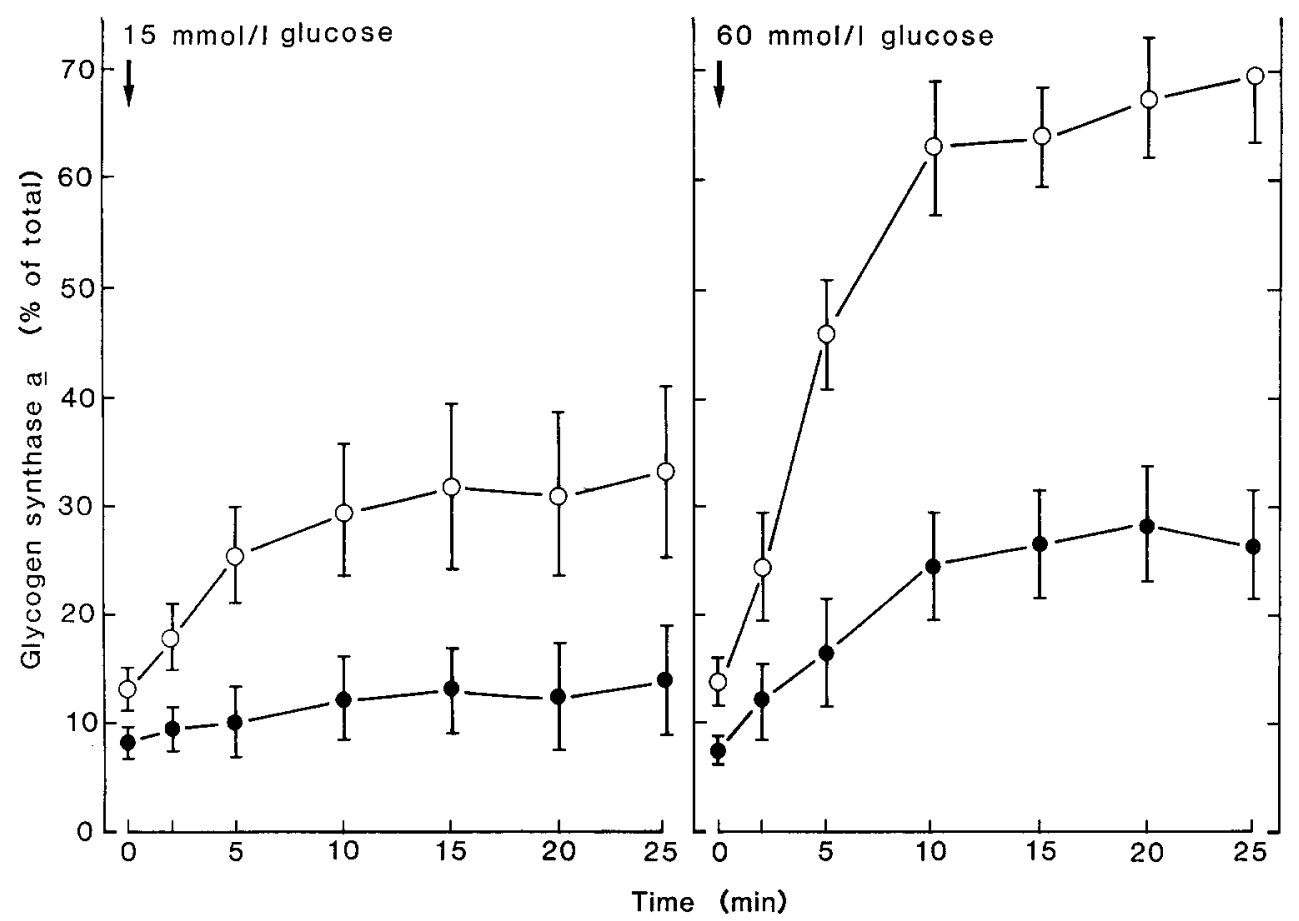

Fig. 1. Effect of glucose on the activity of glycogen synthase in isolated hepatocytes from BB-rats. Liver cells isolated from 7 normal (O) and from 7 diabetic rats (O) were preincubated during $15 \mathrm{~min}$ in the presence of $2 \mathrm{mmol} / \mathrm{l}$ glucose. Subsequently, $(\downarrow)$ the glucose concentration was raised by $15 \mathrm{mmol} / \mathrm{l}$ (a) or $60 \mathrm{mmol} / \mathrm{l}$ (b) and samples were taken at the indicated times for the assay of glycogen synthase. Vertical bars (I) represent $\pm S E M$. The concentrations of synthase $a+b$ were $5.93 \pm 0.82$ and $6.99 \pm 1.03 \mathrm{U} / \mathrm{g}$ protein in the non-diabetic and in the diabetic group, respectively $(p=0.43)$

\section{Statistical analysis}

The results are expressed as means $\pm S E M$ for the indicated number ( $n$ ) of observations. The unpaired, two-tailed Student's $t$-test with unpooled variance was used to calculate the statistical significance of the differences.

\section{Results}

Table 1 lists various characteristics of diabetic BB rats (4-5 days after the onset of glycosuria) and of matched non-diabetic littermates. The diabetic animals had lost about $20 \%$ body weight and $30 \%$ liver mass. They were markedly hyperglycaemic and hypoinsulinaemic. Their livers were almost depleted of glycogen. The total concentration of glycogen synthase $(a+b)$ was somewhat increased in the diabetic livers, but a significantly lower proportion of the enzyme was in the active form.

Figure 1 shows the effect of glucose on the activity of glycogen synthase in hepatocytes isolated from BB- rats. Liver cells from normoglycaemic animals responded to an addition of $15 \mathrm{mmol} / 1$ glucose with an activation of glycogen synthase until $30 \%$ of the total $(a+b)$ activity, but no activation occurred in hepatocytes from diabetic rats. In the presence of $60 \mathrm{mmol} / 1$ glucose glycogen synthase reached a final activity of $70 \%$ in the control group, but less than $30 \%$ after the development of diabetes. The initial rate of activation of glycogen synthase was 4 to 6 -fold lower in the diabetic cells. In agreement with previous data [6] we observed that the synthase phosphatase activity in liver homogenates from the diabetic animals was decreased by $56 \%$ (Table 1 ). The magnitude of the latter loss corresponded well with the degree to which the activation of glycogen synthase by a saturating concentration of glucose was impaired in intact cells (Fig. 1b). It is likely that, in vivo, hepatic glycogen synthesis is further hampered by the high glucagon/insulin ratio, which is expected to increase the activity of the cyclicAMP-dependent protein kinase $[1,2]$.

Data on mice with non-insulin-dependent diabetes 
are illustrated in Table 1. At the time of killing the $\mathrm{db} / \mathrm{db}$ mice were markedly obese, hyperglycaemic and hyperinsulinaemic. Hammad et al. [7] observed that the pattern of liver glycogen deposition after refeeding was close to normal in $\mathrm{db} / \mathrm{db}$ mice. We observed that the post-absorptive hepatic glycogen stores were in fact $44 \%$ higher in the latter animals than in the wild type (Table 1). Glycogen is a potent inhibitor of glycogen-synthase phosphatase [1]. This may explain that the state of activation of hepatic glycogen synthase was significantly lower in the $\mathrm{db} / \mathrm{db}$ mice (Table 1 ). An important point is that the development of the noninsulin-dependent diabetic state did not affect the activity of glycogen-synthase phosphatase (Table 1). This observation corroborates previous findings [8] that the activation of endogenous glycogen synthase proceeded normally during incubation of liver homogenates from $\mathrm{db} / \mathrm{db}$ rats.

\section{Discussion}

On two accounts, the present findings allow us to interpret unambiguously previous observations on hepatic glycogen metabolism in alloxan-diabetic rats [1-3]. First, the impaired activation of glycogen synthase in hepatocytes [2] and the loss of synthase phosphatase activity [3] were also observed in BB rats with spontaneous insulin-dependent diabetes. Therefore, these changes are not connected to the use of alloxan. They are general characteristics of insulin-dependent diabetes.

The second point concerns the mechanism of the impaired activity of glycogen-synthase phosphatase. Miller et al. [9] have investigated the restoration of glycogen-synthase phosphatase activity in serum-free primary cultures of hepatocytes from alloxan-diabetic rats. Rather surprisingly, the essential factors appeared to be cortisol and thyroid hormone. Insulin alone was ineffective. In the presence of the other hormones it merely enhanced the rate of recovery of synthase phosphatase [9]. This and other considerations led us to the hypothesis that the loss of synthase-phosphatase activity might be the result of a nonenzymatic glycosylation $[1,3]$. It is now widely accepted that such glycosylation of proteins plays a role in the pathogenesis of some long-term complications of diabetes [10]. Moreover, there are several reports [10] that the activity of enzymes with a short half-life can also be affected. Since the intrahepatic glucose concentration equals the plasma glucose level, hepatic proteins can be a target for glycosylation. However, our observation that the synthase phosphatase activity is not affected in non-insulin-dependent diabetes, in spite of marked hyperglycaemia, proves that a putative glycosylation cannot explain the decreased synthase phosphatase activity in insulin-dependent diabetes. The results indicate that it is the shortage of insulin that causes the loss of hepatic synthase phosphatase activity in the latter condition.

Acknowledgements. Financial support came from the Belgian Fund for Medical Scientific Research (grant 3.0041.85). We thank Professor R.Bouilion for kindly providing the BB rats. Ms N.Sente provided expert technical assistance.

\section{References}

1. Stalmans W, Bollen M, Mvumbi L (1987) Control of glycogen synthesis in health and disease. Diabetes Metab Rev 3: 127-161

2. Bollen M, Hue L, Stalmans W (1983) Effects of glucose on phosphorylase and glycogen synthase in hepatocytes from diabetic rats. Biochem J 210: 783-787

3. Bollen M, Stalmans W (1984) The hepatic defect in glycogen synthesis in chronic diabetes involves the G-component of synthase phosphatase. Biochem J 217: 427-434

4. Vandebroeck A, Bollen M, De Wulf H, Stalmans W (1985) An assessment of the importance of intralysosomal and of $\alpha$-amylolytic glycogenolysis in the liver of normal rats and of rats with a glycogen-storage disease. Eur J Biochem 153: 621-628

5. Heding LG (1972) Determination of total serum insulin (IRI) in insulin-treated diabetic patients. Diabetologia 8: 260-266

6. Appel MC, Like AA, Rossini AA, Carp DB, Miller TB Jr (1981) Hepatic carbohydrate metabolism in the spontaneously diabetic Bio-Breeding Worcester rat. Am J Physiol 240: E83-E87

7. Hammad ESF, Striffler JS, Cardell RR Jr (1982) Morphological and biochemical observations on hepatic glycogen metabolism in genetically diabetic $(\mathrm{db} / \mathrm{db})$ mice. Diabete Metab 8: 147-153

8. Roesler WJ, Khandelwal RL (1985) Age-related changes in hepatic glycogen metabolism in the genetically diabetic $(d b / d b)$ mouse. Diabetes 34: 395-402

9. Miller TB Jr, Garnache A, Cruz J (1984) Insulin regulation of glycogen synthase phosphatase in primary cultures of hepatocytes. J Biol Chem 259: 12470-12474

10. Vlassara H, Brownlee M, Cerami A (1986) Nonenzymatic glycosylation: role in the pathogenesis of diabetic complications. Clin Chem 32: B37-B41

Received: 9 May 1988

and in revised form: 11 July 1988

Prof. W. Stalmans

Afdeling Biochemie

KULeuven Campus Gasthuisberg

B-3000 Leuven

Belgium 